\title{
PERANCANGAN MEDIA PEMBELAJARAN BERBASIS ANDROID PADA MATERI TRIGONOMETRI UNTUK PESERTA DIDIK KELAS X DI SMA NEGERI 1 CIPATUJAH
}

\author{
Nita Yunitasari ${ }^{1}$, Sulidar Fitri ${ }^{2}$, Muhammad Taufiq ${ }^{3}$ \\ ${ }^{1,2,3)}$ Pendidikan Teknologi Informasi FKIP Universitas Muhammadiyah Tasikmalaya \\ email : nitayunitasari19@gmail.com ${ }^{1)}$,sfitri@umtas.ac.id ${ }^{2}$,
}

\begin{abstract}
Abstraksi
Media pembelajaran berbasis android ini dirancang melalui enam tahapan yaitu tahapan system/information engineering, software requirement analysis, design, coding implamantation, testing, dan maintance. Media pembelajaran berbasis android ini di gunakan untuk proses pembelajaran mengenai materi sudut pengukuran dan identitas trigonometri. Perancangan media pembelajaran berbasis android dibuat dengan menggunakan Microsoft PowerPoint yang sudah terpasang iSpring Suite versi 9.7.2 dan Website 2 Apk Builder yang berfungsi untuk mengubah file *.pptx menjadi file *.apk untuk bisa di unduh di smartphone. Pembuatan materi menggunakan Microsoft PowerPoint dan membuat soal dengan menggunakan iSpring Suite versi 9.7.2 yang dijadikan sebagai uji kompetensi untuk peserta didik setelah mempelajari materi kemudian di konversikan menggunakan Website 2 Apk Builder. Pengujian menggunakan metode black box, setiap aspek memiliki hasil yang dapat disimpulkan berhasil dan layak untuk diujicobakan ke peserta didik. Uji kelayakan berupa kuesioner dari ahli media memperoleh angka sebesar 39 dengan klasifikasi baik, hasil uji kelayakan dari ahli materi memperoleh angka sebasar 47 denga klasifikasi sangat baik, dan hasil dari respon peserta didik memperoleh angka sebesar 39,63 dengan klasifikasi baik. Hasil tersebut dapat disimpulkan layak untuk diujicobakan ke peserta didik jika angka yang diperoleh termasuk kedalam klasifikasi baik. Dengan demikian media pembelajaran berbasis android pada materi trigonometri ini layak untuk digunakan untuk proses pembelajaran.
\end{abstract}

Kata Kunci : Perancangan, Android, Media Pembelajaran

\begin{abstract}
This Android-based learning media is designed through six stages, namely the stages of system / information engineering, software requirements analysis, design, coding implementation, testing, and maintenance. This Android-based learning media is used for the learning process regarding measurement angle material and trigonometric identities. The design of Android-based learning media was made using Microsoft PowerPoint which has been installed with iSpring Suite version 9.7.2 and Website 2 Apk Builder which functions to convert *.pptx files into *.apk files for download on smartphones. Making material using Microsoft PowerPoint and making questions using iSpring Suite version 9.7.2 which is used as a competency test for students after studying the material then converted using Website 2 Apk Builder. Testing using the black box method, every aspect has results that can be concluded successful and feasible to be tested on students. The feasibility test in the form of a questionnaire from a media expert obtained a number of 39 with good classification, the results of the feasibility test from the material expert obtained a score of 47 with a very good classification, and the results of the student's response got a number of 39.63 with a good classification. These results can be concluded that it is feasible to be tested on students if the numbers obtained are classified as good. Thus the Android-based learning media on trigonometric material is feasible to be used for the learning process.
\end{abstract}

Keywords : Design, Android, Leraning Media 


\section{PENDAHULUAN}

Penggunaan android menjadi hal yang sangat penting dikalangan umum termasuk kalangan remaja yang duduk di bangku sekolah. Di era teknologi yang semakin pesat seperti dalam proses belajar-mengajar sebagian besar belajar melalui android pada dunia pendidikan karena mempermudah bagi tenaga pendidik dalam menyampaikan materi baik didalam kelas maupun tenaga pendidik yang berhalangan hadir. Pembelajaran matematika pada umumnya sangat penting bagi peserta didik mulai dari sekolah dasar untuk membekali kemampuan berpikir secara logis, kritis, dan sistematis. Oleh karena itu agar peserta didik dapat mencapai tujuan pembelajaran diperlukan kegiatan pembelajaran inovatif yang memfasilitasi peserta didik dalam belajar sehingga peserta didik paham dengan konsep yang disajikan oleh tenaga pendidik.

Berdasarkan dari hasil belajar yang diperoleh peserta didik kelas X (sepuluh) IPS di Sekolah Menengah Atas Negeri 1 Cipatujah pada mata pelajaran matematika materi trigonometri mendapatkan hasil nilai dibawah rata rata. KKM (Kriteria Ketuntasan Minimal) yang diberikan untuk sebuah pencpaian hasil belajar yaitu 75, namun rata rata hasil yang diperoleh peserta didik adalah nilai 70. Dari pernyataan tersebut dapat disimpulkan bahwa permasalahan yang dialami oleh peserta didik rata-rata dari hasil belajar yang kurang maksimal atau dibawah KKM (Kriteria Ketuntasan Minimal), hal tersebut disebabkan oleh keterbatasan media yang kurang efektif untuk digunakan karena hanya memiliki satu unit proyektor dan di gunakan secara bergantian dengan jumlah 15 rombongan belajar, sehingga tidak ada warna baru dalam pembelajaran yang menarik perhatian peserta didik agar lebih giat dalam belajar. Berdasarkan uraian diatas, menjadi perhatian penting untuk memberikan sebuah inovasi baru berupa media pembelajaran berbasis android yang diharapkan bisa membantu peserta didik dalam proses pembelajaran agar mendapat hasil yang maksimal.

Dari perumusan masalah tersebut, didapat tujuan penelitian yaitu menghasilkan perancangan media pembelajaran berbasis android pada materi trigonometri untuk peserta didik kelas X di SMAN 1 Cipatujah dengan menggunakan metode waterfall (air terjun) dan untu mengetahui tingkat kelayakan dari media pembelajaran berbasis android yang telah dirancang ini untuk dipergunakan kepadapeserta didik kelas X di SMAN 1 Cipatujah. Adapun untuk batasan masalah dalam penelitan ini adalah media pembelajaran berbasis android di implementasikan untuk kelas X, media pembelajaran berbasis android di khususkan pada materi trigonometri,dan media pembelajaran berbasis android ini menyediakan fitur perhitungan skor pada menu uji kompetensi yang hasilnya akan dikirim secara otomatis melalui $e$-mail / g-mail.

\section{a. Perancangan Aplikasi}

Konsep merancang multimedia merupakan aplikasi multimedia yang akan dibuat. Untuk dapat merancang konsep dalam membuat aplikasi multimedia dibutuhkan kreatifitas. Kreatifitas adalah kemampuan untuk menyajikan gagasan atau ide baru. Sedangkan inovasi merupakan aplikasi dari gagasan atau ide baru tersebut. Untuk menciptakan ide yang orisinil tidaklah mudah, maka dapat digunakan beberapa teknik untuk menciptakan ide, yaitu penyesuaian (adaptasi), Multimedia yang telah ada dianggap belum sesuai dengan lingkungan yang dituju. Merancang konsep analisis sistem bekerjasama dengan pemakai, mungkin juga bekerjasama dengan profesional komunikasi seperti produser, sutradara, penulis naskah, editor elektronik terlibat dalam merancang konsep yang menentukan keseluruhan pesan dan membuat aliran (urutan) pada aplikasi multimedia yang akan dibuat. Untuk dapat merancang konsep dalam membuat aplikasi multimedia dibutuhkan kreativitas

\section{b. Andorid}

Menurut Herlinah, S.Kom, M.Si., dan Musliadi KH, S.Kom, dalam bukunya yang berjudul "Pemrograman Aplikasi Android dengan Android Studio, Photoshop, dan Audition" menyatakan bahwa "Android merupakan sistem operasi yang banyak digunakan pada perangkat gerak yang dewasa ini sangat terkenal dan populer digunakan pada ponsel cerdas [2]. Android juga meupakan platform pemrograman yang dikembangkan oleh Google untuk ponsel cerdas dan perangkat seluler lainnya, misalnya tabelt. Android bisa dijalankan di beberapa macam perangkat yang dikembangkan oleh banyak vendor ponsel cerdas yang berbeda. Android menyertakan paket pengembangan perangkat lunak untuk penulisan kode asli dan perakitan modul perangkat lunak dalam membuat aplikasi bagi pengembang android. Selain menyediakan paket pengembang aplikasi android, android juga menyediakan pasar untuk mendistribusikan aplikasi yang telah selesai dikembangkan. Dengan lengkapnya fasilitas yang telah disediakan oleh android, dapat dikatakan bahwa secara keseluruhan android menciptakan ekosistem sendiri.

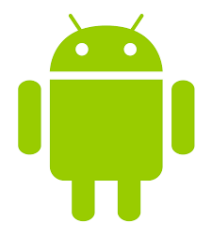

Gambar 2.1 Logo Android [1] 


\section{c. Media Pembelajaran}

Menurut Drs. Hj Rodhatul Jennah, (2009: 2) Media adalah komponen sumber belajar atau wahana flsik yang mengandung materi instruksional di lingkungan pebelajar yang dapat merangsang pebelajar untuk belajar [3]. Dengan demikian media pembelajaran adalah segala sesuatu yang dapat digunakan untuk menyalurkan pesan (bahan pembelajaran), sehingga dapat merangsang perhatian, minat, pikiran dan perasaan siswa dalam kegiatan pembelajaran untuk mencapai tujuan pembelajaran tertentu.

\section{d. Materi Trigonometri}

Menurut Yudhistira (2008: 234) Trigonometri dalam bahasa yunani adalah pengukuran segitiga merupakan bagian dari matematika yang mempelajari hubungan antara sisi-sisi dan sudut-sudut pada suatu segitiga [6]. Dalam penerapannya, trigonometri digunakan dibidang navigasi, pengukuran, fotografi, fisika, dan sebaginya. sebagai contoh dalam navigasi pelayaran, konsep dasar perbandingan trigonometri digunakan dalam menentukan arah dan jarak dari satu tempat ke tempat yang lain.

\section{METODE PENELITIAN}

Metode penelitian ini berfokus pada perancangan sebuah media pembelajaran. Perancangan ini menggunakan metode waterfall. Metode waterfall adalah proses pengembangan perangkat lunak berurutan, dimulai dari analisis, desain, implementasi, pengujian dan pemeliharaan [4]. Metode Waterfall memiliki tahapan-tahapan sebagai berikut:

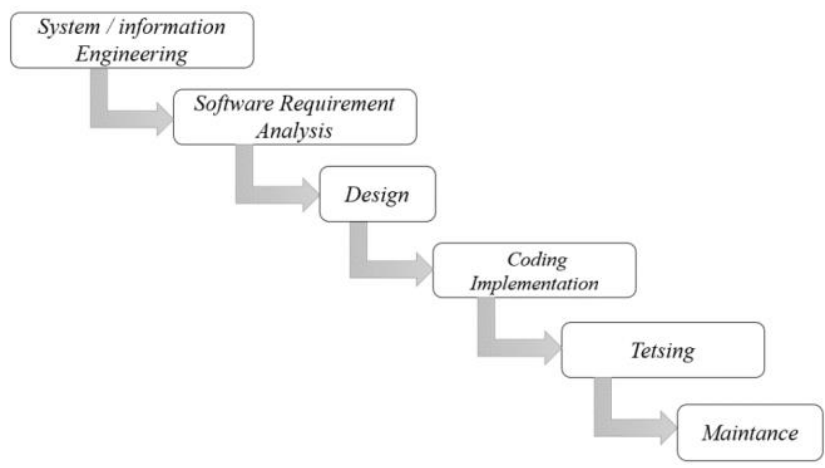

Gambar 3.1 Metode Waterfall

\section{System / Infromation Engineering}

Tahap pertama diawali dengan mencari kebutuhan dari keseluruhan sistem yang akan diaplikasikan ke dalam bentuk software [5].

\section{Software Requirement Analysis}

Analisis kebutuhan software di lakukan melalui 2 tahapan untuk memenuhi proses perancangan android pada materi trigonometri untuk dijadikan sebagai media pembelajaran.

a. Kebutuhan Fungsional

Kebutuhan fungsional adalah kebutuhan yang berisi sistem atau layanan yang harus disediakan oleh sistem. Kebutuhan fungsional tersebut adalah sebagai berikut:

Tabel 3.1 Kebutuhan Fungsional

\begin{tabular}{|c|c|}
\hline Kebutuhan & Penjelasan \\
\hline $\begin{array}{l}\text { Menyediakan fasilitas menu belajar yang } \\
\text { berisi tentang materi trigonometri }\end{array}$ & Menampilkan data \\
\hline $\begin{array}{l}\text { Menyediakan fasilitas menu } \mathrm{Uji} \\
\text { Kompetensi yang berisi tentang soal }- \text { soal } \\
\text { trigonometri }\end{array}$ & Menampilkan data \\
\hline $\begin{array}{l}\text { Menyediakan fasilitas form Log In pada } \\
\text { menu Uji Kompetensi }\end{array}$ & Input user, password, dan Log In \\
\hline Menyediakan fasilitas menu Informasi & Menampilkan data \\
\hline $\begin{array}{l}\text { Menyediakan fasilitas hasil pengerjaan soal } \\
\text { melalui } e \text {-mail }\end{array}$ & $\begin{array}{l}\text { Menampilkan laporan hasil dari pengisian soal melalui } \\
e \text {-mail yang bisa di cetak }\end{array}$ \\
\hline
\end{tabular}


b. Kebutuhan Non fungsional

Kebutuhan non fungsional adalah kebutuhan yang menitikberatkan pada property perilaku yang dimiliki sistem. Kebutuhan non fungsional tersebut adalh sebagi berikut:

Tabel 3.2 Kebutuhan Non Fungsional

\begin{tabular}{|c|l|}
\hline Parameter & \multicolumn{1}{|c|}{ Requirement } \\
\hline Availability & Perangkat lunak mampu berjalan aktif dengan semestinya \\
\hline Reliability & Menjamin pemasukan data \\
\hline Ergonomy & $\begin{array}{l}\text { Menjamin kenyamanan pengguna dengan antar muka yang semenarik } \\
\text { mungkin / user friendly }\end{array}$ \\
\hline Portability & Mampu berjalan pada platform android di semua versi \\
\hline Response Time & Mampu menampilkan informasi dengan cepat \\
\hline Security & Batas penggunaan Aplikasi dapat diakses oleh pengguna dengan \\
\hline Value & Meampu menyimpan data banayk \\
\hline Bahasa komunikasi & Menggunakan Bahasa indonesia \\
\hline & \\
& \\
\hline
\end{tabular}

\section{Design}

Setelah tahapan pada analisis kebutuhan selesai, selanjutnya dilakukan tahapan desain yang dijabarkan sebagai berikut:

1) Mendesain flowchart untuk media pembelajaran aplikasi android pada materi trigonometri

2) Mendesain hipo diagram untuk memberikan gambaran dari tampilan media yang akan di buat

\section{Coding Implementation}

Pada tahap ini, perancangan perangkat lunak direalisasikan sebagai hasil serangkaian penggabungan dari desain flowchart dan hipo diagram. Pada tahapan ini dilakukan realisasi hasil dari desain flowchart dan hipo diagram sehingga menghasilkan aplikasi media pembelajaran

\section{Testing}

Pengujian ini dilakukan untuk menunjukkan fungsi- fungsi pada aplikasi yang dibuat tentang cara operasi dan kegunaannya, apakah keluaran data sesuai dengan yang diharapkan. Pengujian ini dilakukan untuk mengetahui apakah masih terjadi kesalahan fungsi dalam aplikasi atau aplikasi sudah dapat dijalankan dengan benar.

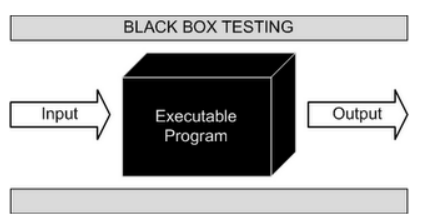

Gambar 3.2 Black Box Testing

\section{Maintance}

Tahapan ini merupakan tahapan terakhir dalam metode waterfall. Tahap pemeliharaan ini mencakup pada kesalahan - kesalahan dari tahapan sebelumnya yang belum terkoreksi. Pemeliharaan ini dilakukan oleh admin untuk meningkatkan kualitas dari media agar menjadi lebih baik

\section{HASIL DAN PEMBAHASAN}

\section{A. Hasil Penelitian}

\section{Deskripsi Media Pembelajaran Berbasis Android}

Media pembelajaran berbasis android pada materi trigonometri ini digunakan untuk peserta didik kelas $\mathrm{X}$ di sekolah SMA Negeri 1 Cipatujah. Media pembelajaran ini dibuat dengan menggunakan Microsoft PowerPoint yang di dalamnya sudah terpasang software yang bernama iSpring Suite versi 9.7.2 dan 
menggunakan software Website 2 Apk Builder berfungsi untuk mengconversikan dari file *.pptx menjadi file *.apk yang nantinya dapat di pasang (install) pada android.

\section{Design}

a. Flowchart

Flowchart dapat diartikan sebagai rancangan yang menggambarkan proses alur kerja dari program. Alur kerja program dapat digambarkan sebagai berikut:

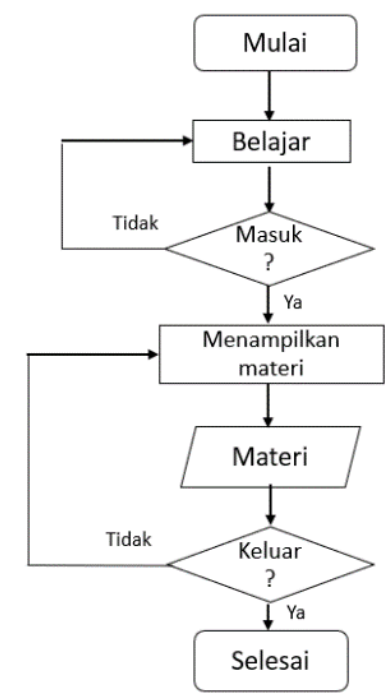

Gambar 4.1 Rancangan Flowcgart Mneu Belajar

\section{b. Hipo Diagram}

Hipo diagram dapat di artikan sebagai sketsa gambar tampilan awal setelah tahap desain flowchart yang disusun sesuai dengan alur yang telah dirancang oleh flowchart. Adapun gambaran dari hipo diagram yang telah di rancang adalah sebagai berikut:

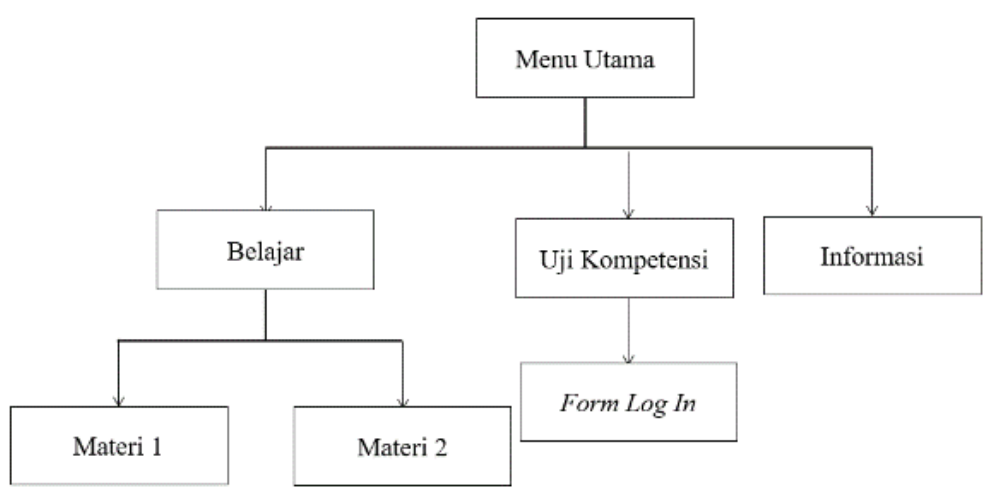

Gambar 4.3 Rancangan Hipo Diagram

\section{Coding Implementation}

Setelah semua rancangan telah terpenuhi, kemudian dilanjutkan ke tahap impelemntasi. Adapun tahap impelentasi rancangan adalah sebagai berikut:

a. Implementasi Desain kedalam Program

Tahap impelentasi adalah tahap dimana hasil dari rancangan flowchart dan hipo diagram direalisaikan menggunkaan software Microsoaft PowerPoint yang didalamnya telah terpasang iSpring Suite versi 9.7.2 untuk menginput materi yang telah di sediakan. Pada iSpring Suite versi 9.7.2 berfungsi untuk menginput soal - soal dengan fitur yang lengkap. Setelah semua rancangan di realisasikan kemudian di konversikan dari file .pptx menjadi file .apk dengan menggunakan software yang telah terpasang bernama Website 2 Apk Builder. 
b. Implementasi Tampilan Program

Impelemntasi tampilan program yaitu hasil impelementasi dari rancangan flowchart dan hipo diagram kedalam program. Setelah program selesai, kemudian direalisasikah hasil tampilan progam.

Pada bagian menu utama terdapat 3 menu utama yaitu Menu Belajar, Menu Uji Kompetensi, dan Menu Informasi. Dapat dilihat pada gambar 4.3

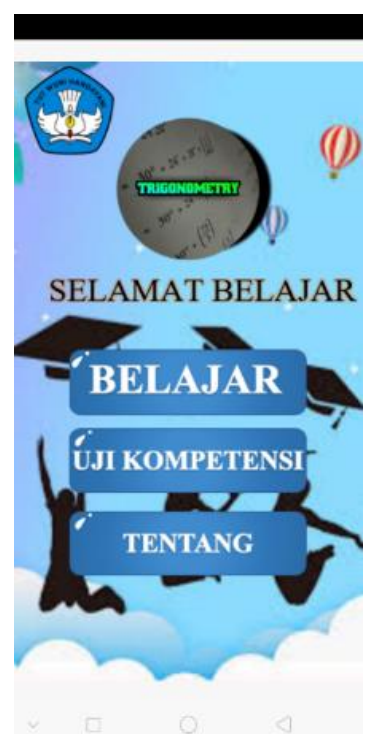

Gambar 4.3 Implementasi halaman menu utama

\section{Black Box Testing}

Pengujian menggunakan black box semua aspek pengujian memperoleh kesimpulan berhasil atau valid karena semua hasil yang diharapkan dapat mencapai tujuan yang maksimal. Dengan demikian, media pembelajaran berbasis android pada materi trigonometri untuk peserta didik kelas X di SMA N 1 Cipatujah layak di ujicobakan untuk proses pembelajaran.

Tabel 4.3 Hasil Pengujian Black Box

\begin{tabular}{|l|l|l|l|c|}
\hline No & $\begin{array}{l}\text { Aspek } \\
\text { Pengujian }\end{array}$ & \multicolumn{1}{|c|}{ Bentuk Pengujian } & \multicolumn{1}{|c|}{ Hasil yang diharapkan } & Kesimpulan \\
\hline 1. & $\begin{array}{l}\text { Halaman } \\
\text { Utama }\end{array}$ & Membuka tombol mulai & Dapat meuju menu utama & Valid \\
\hline 2. & $\begin{array}{l}\text { Menu } \\
\text { utama }\end{array}$ & Menekan tombol belajar & Dapat menampilkan halaman belajar & Valid \\
\cline { 3 - 5 } & $\begin{array}{l}\text { Menekan tombol Uji } \\
\text { Kompetensi }\end{array}$ & $\begin{array}{l}\text { Dapat menampilkan halaman Login untuk } \\
\text { memulai menjawab soal }\end{array}$ & Valid \\
\cline { 3 - 6 } & $\begin{array}{l}\text { Menekan salah satu } \\
\text { tombol jawaban yang } \\
\text { benar berjumlah 5 } \\
\text { menurun }\end{array}$ & $\begin{array}{l}\text { Dapat menampilkan jawaban } \text { correct (benar) } \\
\text { / incorrect (salah) }\end{array}$ & Valid \\
\cline { 3 - 6 } & $\begin{array}{l}\text { Proses pengiriman hasil } \\
\text { skor yang diperoleh ke } e- \\
\text { mail }\end{array}$ & Dapat menampilkan hasil jawaban di $e-$-mail & Valid \\
\cline { 3 - 6 } & $\begin{array}{l}\text { Menekan tombol } \\
\text { Informasi }\end{array}$ & Dapat menampilkan informasi & Valid \\
\hline 3. & Menu Exit & $\begin{array}{l}\text { Menekan tombol back } \\
\text { pada layar Smartphone }\end{array}$ & Dapat keluar dari aplikasi & Valid \\
\hline
\end{tabular}

\section{Maintence}

Tahapan ini meurpakan tahapan terakhir pada metode waterfall. Pemeliharaan mencakup pada kesalahan - kesalahan pada tahap sebelumnya. Pemeliharaan sistem dapat dilakukan untuk meningkatkan kualitas sistem agar menjadi lebih baik. Pada tahap ini peneliti melakukan perbaikan pada desain, yaitu merubah warna background dan tombol navigasi agar menjadi konsisten. 


\section{B. Pembahasan}

Perancangan media pembelajaran berbasis android pada materi trigonomteri untuk kelas X SMAN 1 Cipatujah menggunakan teknik analisis data deskriptif kuantitatif. Deskriptif kuantitatif menunjukan bahwa hasil yang diperoleh dari hasil kelayakan ahli media, hasil kelayakan ahli materi dan respon peserta didik menunjukan pada kriteria layak digunakan untuk proses pembelajaran jika angka yang diperoleh termasuk kedalam klasifikasi baik.

Hasil yang diperoleh pada penelitian ini menunjukan bahwa hasil perancangan media pembelajaran berbasis android pada materi trigonometri nilai kelayakan dari ahli media memeproleh angka sebesar 39 termasuk kedalam klasifikasi Baik, Hasil yang di dapat dari pengujian kelayakan materi memperoleh angka sebesar 47 dan termasuk kedalam klasifikasi Sangat Baik. Hasil respon dengan menggunakan kuesioner dari peserta didik menunjukan angka sebesar 39,63 termasuk kedalam klasifikasi Baik dan disimpulkan mendapat respon yang baik, dan dapat dilihat pada gambar diagram di bawah ini.

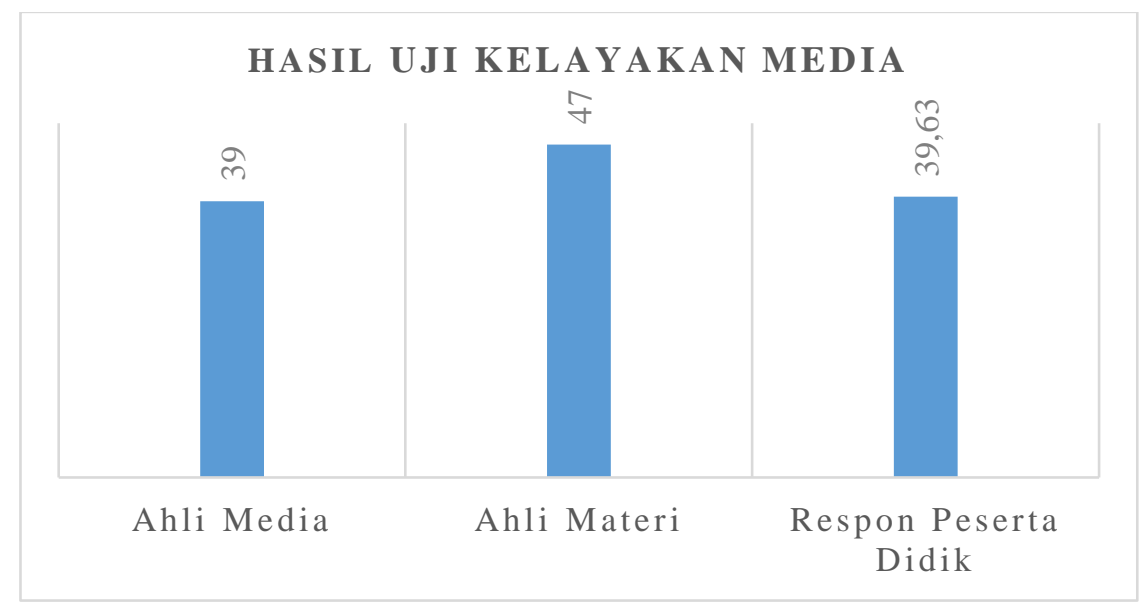

Gambar 4.4 Diagram Hasil Uji Kelayakan

Keunggulan dari media pembelajaran ini adalah perhitungan skor pada menu uji kompetensi yang hasilnya akan dikirim otomatis melalui $e$-mail dan tenaga pendidik akan mengetahui peserta didik yang mengerjakan soal dan yang tidak mengerjakan soal.

\section{KESIMPULAN}

Dalam perancangan media pembelajaran berbasis android pada materi trigonometri untuk peserta didik kelas $\mathrm{X}$ di SMAN 1 Cipatujah menunjukan bahwa setelah melalui beberapa tahapan untuk sebuah perancangan aplikasi memperoleh hasil sebagai berikut:

1. Aplikasi android untuk media pembelajaran pada materi trigonometri telah dirancang melalui model perancangan waterfall dengan tahapan mulai dari analisis kebutuhan untuk perancangan aplikasi sampai dengan tahap pengujian kelayakan dari ahli media, ahli materi serta respon peserta didik terhadap aplikasi android yang telah di buat.

2. Kelayakan dari hasil pengujian black box yang di dapat dari semua aspek pengujian pada halaman utama, menu utama dan menu exit dapat disimpulkan berhasil.

3. Kelayakan dari aplikasi android yang telah di buat memperoleh hasil dari ahli media sebesar 39 dengan klasifikasi Baik dan memperoleh keriteri layak untuk diuji cobakan ke peserta didik.

4. Hasil kelayakan dari ahli materi memperoleh angka sebesar 47 dengan klasifikasi Baik dan memperoleh kriteria layak untuk diuji cobakan ke peserta didik.

5. Hasil respon angket dari pesrerta didik memperoleh angka sebesar 39,63 dengan klasifikasi Baik sehingga aplikasi ini disimpulkan mendapat respon yang baik dari para peserta didik dan layak untuk digunakan dalam proses pembelajaran. 


\section{DAFTAR PUSTAKA}

[1] Firly Nadia. Create Your own Android Aplication. Penerbit: PT Elex Media Kompitudo. Jakarta. 2018

[2] Herlinah, Muslidi. Pemrograman Aplikasi Android dengan Android Studio, Photoshop, dan Audition. Penerbit: PT Elex Media Komputindo. Jakarta, 2019

[3] Jennah Rodhatul. Media Pembelajaran. Penerbit: Antasari Press. Banjarmasin, 2009

[4] Pressman dan P. Bruce R. Maxim. Software Engineering APractitioner's Approach. Singapore: Mc Graw Hill Education. 2015.

[5] Pressman, R.S. Software Engineering: a practitioner's approach. P. Roger S. 2010

[6] Yudhistira. Matematics: Ghalia Indonesia. Jakarta, 2008

\section{BIODATA PENULIS}

Nita Yunitasari, memperoleh gelar Sarjana Pendidikan (S.Pd) Program Studi Pendidikan Teknologi Informasi Universitas Muhammadiyah Tasikmaaya (UMTAS) lulus pada tahun 2020.

Sulidar Fitri, memperoleh gelar Sarjana Teknik Informatika (S.Kom) di Universitas Amikom Yogyakarta lulus pada tahun 2010, lalu melanjutkan studi program Magister Teknik Informatika (M.Sc) di Asia University Taiwan lulus pada tahun 2012, dan saat ini sebagai staff pengajar Program Studi Pendidikan Teknologi Informasi Universitas Muhammadiyah Tasikmalaya (UMTAS).

Ir. Muhammad Taufiq, memperoleh gelar Sarjana Teknik Perminyakan (S.T), lalu melanjutkan studi program Magister Manajemen dan Magister Teknik Informatika (M.Kom), saat ini sebagai Staf pengajar Program Studi Pendidikan Teknologi Informasi Universitas Muhammadiyah Tasikmalaya (UMTAS). 